\title{
Methods of evaluation of the ovarian reserve
}

\author{
Ibrahim A. Abdelazim¹,2, Mohannad Abu-Faza', Svetlana Shikanova³, Bakyt Karimova³, \\ Gulmira Zhurabekova ${ }^{4}$, Manal M. Maghrabi ${ }^{5}$
}

'Department of Obstetrics and Gynecology, Ahmadi hospital, Kuwait Oil Company, Ahmadi, Kuwait ${ }^{2}$ Department of Obstetrics and Gynecology, Ain Shams University, Cairo, Egypt

${ }^{3}$ Department of Obstetrics and Gynecology No. 1, Marat Ospanov, West Kazakhstan State Medical University (WKSMU), Aktobe, Kazakhstan

${ }^{4}$ Department of Normal and Topographical Anatomy, Marat Ospanov, West Kazakhstan State Medical University (WKSMU),

Aktobe, Kazakhstan

${ }^{5}$ Department of Obstetrics and Gynecology, Alwakra hospital, Hamad Medical Corporation, Alwakra, Oatar

\begin{abstract}
The chances of pregnancy decrease with the natural aging process of the infertile couple. During treatment of an infertile couple, the clinicians are usually asked questions about the chance of conception. Ovarian reserve describes the reproductive ability of the woman. An ideal ovarian reserve test should be affordable, convenient and sensitive. Ovarian reserve tests help to predict a poor response or hyper-response to ovarian stimulation and help to formulate the treatment plan in an infertile couple. Decreased ovarian reserve refers to women whose ovarian response to exogenous gonadotropin stimulation is reduced compared to similar women of the same age.

Key words: ovarian, reserve, evaluation.
\end{abstract}

Corresponding author: Ibrahim A. Abdelazim, Department of Obstetrics and Gynecology, Ain Shams University, Cairo, Egypt and Ahmadi Kuwait Oil (KOC) Company Hospital, P.O. Box: 9758, 61008 Ahmadi, Kuwait, phone: +965-66551300, e-mail: dr.ibrahimanwar@gmail.com 


\section{Introduction}

Ovarian reserve describes the reproductive ability of the woman, through identification of the number and the quality of the oocytes available in her ovaries [1].

It also guides the clinician to decide about the treatment and individualize the treatment protocols. Ovarian reserve is a complex clinical phenomenon that is greatly influenced by age, genetics and environmental variables. The decline in a woman's ovarian reserve is an irreversible phenomenon. The rate at which a woman loses her primordial follicle varies from person to person [2].

Ovarian reserve refers to the residual oocyte granulosa cell that is available for fertilization at any given age. The quantitative and qualitative decline of these cells is seen with advancing age. Ovarian reserve provides information regarding the follicles that can be stimulated and the oocyte that can be retrieved from the ovary.

Infertility specialists are often faced with the challenge to predict the fertility potential of women. The ovarian reserve test adds more prognostic information to counsel the infertile couple. It helps to identify patients who are likely to have a poor response or hyper-response to gonadotrophin stimulation, but it cannot predict the clinical outcome such as pregnancy $[1,2]$. It helps to differentiate patients with normal ovarian reserve from those with decreased ovarian reserve (DOR) and helps in deciding treatment protocols in women with DOR. It also helps in avoiding aggressive treatment in women with normal reserve. However, it should not be used to exclude an infertile couple from seeking assisted reproductive technology (ART) [1].

Various clinical and biochemical markers have been studied to test the ovarian reserve. An ideal ovarian reserve test should be affordable, minimally invasive, convenient, inexpensive and sensitive with good predictive value [2].

\section{Clinical biomarkers of the ovarian reserve}

\section{Age}

Studies have shown that the fecundability declines after the early $30 \mathrm{~s}$ [3]. The prevalence of infertility increases significantly after the age of 35 years, and by the age of 45 around $99 \%$ of patients are expected to be infertile [4]. Genetic factors, smoking, infections and adnexal surgery are the other determinants of DOR in older women [5]. Tehraninezhad et al. found that age is a good predictor of clinical pregnancy [6].

\section{Menstrual cycle}

The pattern of the menstrual cycle in a woman remains consistent until the late $40 \mathrm{~s}$, after which a gradual shortening in cycle length is seen. In addition, in the late 30 s, a higher serum level of follicular stimulating hormone (FSH) and lower serum levels of inhibin are frequently seen.

Brodin et al. found a significant correlation between the menstrual cycle length and both the pregnancy and the delivery rate [7]. Brodin et al. observed that in women with cycles $>34$ days, the delivery rate was twice as high as in those having cycles $<26$ days. In addition, they found a significant association between the menstrual cycle length and the ovarian response to gonadotropin and the quality of the embryos obtained during in vitro fertilization (IVF) cycles [7].

\section{Biochemical markers of the ovarian reserve}

Ovarian reserve can be evaluated biochemically by the follicle stimulating hormone (FSH), estradiol (E2), inhibin, and anti-Mullerian hormone (AMH).

\section{Follicle stimulating hormone}

Early follicular phase serum FSH (day 3) is commonly used to evaluate the ovarian reserve. It is an indirect marker of the ovarian reserve, based on the feedback inhibition of FSH secretion by the ovarian hormones. At the beginning of the menstrual cycle, the E2 and inhibin B levels inhibit FSH secretion from the pituitary. In women with DOR, the production of ovarian hormones is insufficient with subsequent elevated pituitary FSH secretion.

Van der Steeg et al. found that the chance of pregnancy reduced when the FSH levels exceeded $8 \mathrm{IU} / \mathrm{ml}$ [8]. Ashrafi et al. found that in women with serum FSH levels $\geq 15 \mathrm{IU} /$ $\mathrm{ml}$, fewer oocytes were retrieved, and they found a higher rate of cycle cancellation in women with FSH levels $\geq 15 \mathrm{IU} /$ $\mathrm{ml}$ than women with lower FSH levels, with no significant difference in gonadotropin doses administered [9]. Van Montfrans et al. found that the basal FSH should not be the decisive factor for the initial management of infertile women with regular menstrual cycles [10]. Barbakadze et al. stated that FSH is less reliable than other markers such as AMH and antral follicle count (AFC) for assessing the ovarian reserve [11]. Hence, high FSH levels should not be used alone to exclude women from ART [11].

\section{Estradiol}

It has been observed that women with E2 levels $<20 \mathrm{pg} /$ $\mathrm{ml}$ or $\geq 80 \mathrm{pg} / \mathrm{ml}$ have a higher ART cycle cancellation rate [12]. E2 with FSH assay on cycle day 3 reduced the incidence of false-negative tests obtained when FSH was used alone. The elevation of both indicates poor ovarian response.

E2 has low predictive accuracy and lacks high sensitivity and specificity [13]. It may be used as a guide for starting stimulation with gonadotropins; however, it should not be used alone for assessment of the ovarian reserve and its measurement should be combined with measurement of serum FSH [14].

\section{Inhibin B}

Inhibins are glycoproteins secreted by the granulosa and theca cells. They play a major role in the selection of the dominant follicle and have a regulatory effect on the secretion of FSH [15]. Although Seifer et al. found that women with inhibin B concentration levels $\geq 45 \mathrm{pg} / \mathrm{ml}$ have an increased oocyte retrieval rate and lower cycle cancellation rate [16], other authors found that inhibin B alone is not a very useful marker for assessment of the ovarian reserve [17]. 


\section{Anti-Müllerian hormone}

Anti-Müllerian hormone is a glycoprotein hormone expressed by the granulosa cells of the secondary, pre-antral and antral follicles $<4 \mathrm{~mm}$ in size and its expression decreases as the follicles grow. Anti-Müllerian hormone thus acts as a modulator of follicle recruitment and plays an important role in folliculogenesis [18]. Serum AMH is a reliable marker for ovarian ageing and reproductive status [19].

Women with polycystic ovary syndrome (PCOS) have an increased number of antral follicles compared with normal women [20]. Serum AMH levels were found to be two to three times higher in women with PCOS [21]. Women with low AMH levels prior to IVF may have either an increased risk of cycle cancellation or poor response to stimulation. Van Rooij et al. observed that the serum AMH levels correlated well with pre-induction AFC and the number of oocytes retrieved in ART cycles [22].

A meta-analysis found that AMH levels have similar predictive value as AFC in identifying poor responders [23]. Authors have proposed a cut-off value range of $0.7-0.75 \mathrm{ng} /$ $\mathrm{ml}$ for AMH for the identification of poor responders [24, $25]$. Others have considered serum AMH levels $<0.1-$ $0.35 \mathrm{ng} / \mathrm{ml}$ as the cut-off to minimize false positives [26, 27]. High AMH before IVF is useful in identifying women at risk for hyper-response and ovarian hyper-stimulation syndrome (OHSS).

Vembu et al. suggested a cut-off value of serum AMH to predict the hyper-response in the PCOS group as $6.85 \mathrm{ng} /$ $\mathrm{ml}$ and in the non-PCOS group as $4.85 \mathrm{ng} / \mathrm{ml}$ [28]. In these patients starting a low dose of FSH followed by the use of $\mathrm{GnRH}$ antagonists or using a GnRH antagonist for the triggering of ovulation instead of hCG can be done to prevent the development of OHSS [29].

Serum AMH is useful to detect poor responders, cycle cancellation and OHSS during ART cycles. It is also used for individualization of treatment strategies in patients undergoing IVF treatment.

\section{Ultrasound markers of the ovarian reserve \\ Antral follicle count (AFC)}

Antral follicle count is the total number of follicles observed in both ovaries in the early follicular phase using transvaginal ultrasonography (TVS). It is a very reliable marker of the ovarian reserve [30]. A count of 8-10 considered as a predictor of a normal response. The diameter of the follicle used to define antral follicles ranges from 2 to $10 \mathrm{~mm}$.

Haadsma et al. observed that the number of small antral follicles $2-6 \mathrm{~mm}$ in size declines with age but the number of those $7-10 \mathrm{~mm}$ in size remains constant. They said that the small antral follicle correlates well with the ovarian reserve tests and appears to represent functional ovarian reserve better [31].

Compared to other tests, AFC has the best discriminating potential for a poor ovarian response. It lacks the sensitivity and specificity to predict the occurrence of pregnancy [32]. The presence of $>14$ antral follicles is considered a good predictor for ovarian hyper-response [33].
Maseelall et al. observed that women with $\mathrm{AFC} \geq 11$ (follicles measuring $2-10 \mathrm{~mm}$ present on both ovaries) were more likely to have a live birth [34]. A meta-analysis found that women with AFC $\leq 4$ were 8.7 times more likely not to be pregnant and 37 times more likely to have their cycle cancelled than women with $\mathrm{AFC} \geq 4$ [35].

The sensitivity and the specificity of AFC to predict cycle cancellation was 67 and 95\%; respectively. However, due to low sensitivity the AFC should not be used alone for ART evaluation of ovarian reserve. It is a useful tool for counseling on the low probability of pregnancy and individualizing the treatment protocols in IVF cycles [35].

\section{Ovarian volume}

The routine use of ovarian volume as a predictor of ovarian reserve is controversial. Gibreel et al. observed 93\% and $92 \%$ specificities for the prediction of non-pregnancy and cycle cancellation, respectively with a $3.0 \mathrm{ml}$ cut-off ovarian volume [35]. A meta-analysis of Hendriks et al. found that the predictive value of ovarian volume for poor responders was low [32].

\section{Ovarian blood flow}

Ovarian blood flow has been studied in natural and stimulated reproductive cycles [36]. Shrestha et al. found that high-grade ovarian perifollicular blood flow in the early follicular phase during ovarian stimulation was associated with a higher clinical pregnancy rate [37]. However, the value of the ovarian blood flow is still indeterminate [35].

\section{Dynamic tests for evaluation of the ovarian reserve}

\section{Clomiphene citrate challenge (CCC) test}

The CCC test involves assessment of the FSH on day 3 and day 10 of the menstrual cycle after $100 \mathrm{mg}$ clomiphene citrate (CC) daily from day 5 to day 9 of the menstrual cycle. High serum FSH after clomiphene stimulation suggests DOR [38].

However, a meta-analysis has shown that the CCC test is no better than basal FSH in predicting clinical pregnancy [39].

\section{Exogenous FSH ovarian reserve test}

The exogenous FSH ovarian reserve test (EFORT) measures the increase in E2 and inhibin B $24 \mathrm{~h}$ after the administration of $300 \mathrm{IU}$ of recombinant FSH on cycle day 3 [40]. It tests the functional response of the ovary. Increased levels of E2 and inhibin B after EFORT have a good predictive value for the number of ovarian dominant follicles that can be obtained and/or retrieved after stimulation [40].

\section{Gonadotrophin releasing hormone agonist (GnRH agonist) stimulation test}

In this test, serum estradiol is measured on day 2 of the cycle followed by the subcutaneous administration of a gonadotropin analogue (triptorelin $100 \mu \mathrm{g}$ ). E2 levels are measured on day 3 ( $24 \mathrm{~h}$ later) and values are compared. A rise in E2 level is considered indicative of good ovarian reserve. The 
GnRH agonist stimulation test is a good predictor of poor ovarian reserve, but is not superior to inhibin B or AFC in detection of ovarian reserve [41].

\section{Summary}

The ideal ovarian reserve test should be affordable, minimally invasive, convenient, and inexpensive with good predictive value. It should also have the ability to identify women at risk of developing OHSS. Evidence demonstrates a greater clinical value of AMH and AFC compared to FSH [42]. The AMH has better reliability than other markers to predict the ovarian reserve and the ovarian response to exogenous stimulation [43-45]. Ovarian reserve tests provide prognostic information about women at increased risk of DOR, such as women who: 1) are over 35 years old; 2) have a family history of premature ovarian failure; 3 ) have a past history of ovarian surgery or radiation; 4) have unexplained infertility [1].

According to the NICE guidelines, sufficient ovarian reserve is diagnosed by either AFC of $>4$ or serum AMH level $>5.4 \mathrm{pmol} / \mathrm{l}$ or serum FSH level < 8.9 IU/I [46].

\section{Conflict of interest}

The authors declare no conflict of interest.

\section{References}

1. Practice Committee of the American Society for Reproductive Medicine. Testing and interpreting measures of ovarian reserve. Fertil Steril 2015; 103: e9-17.

2. Toulemon L, Leridon H. Contraceptive practices and trends in France. Fam Plann Perspect 1998; 30: 114-20.

3. Sharara FI, McClamrock HD. The effect of aging on ovarian volume measurements in infertile women. Obstet Gynecol 1999; 94: 57-60.

4. Faddy MJ, Gosden RG, Gougeon A, Richardson SJ, Nelson JF. Accelerated disappearance of ovarian follicles in mid-life: Implications for forecasting menopause. Hum Reprod 1992; 7: 1342-6.

5. Rowe T. Fertility and a woman's age. J Reprod Med 2006; 51: 157-63.

6. Tehraninezhad ES, Mehrabi F, Taati R, Kalantar V, Aziminekoo E, Tarafdari A. Analysis of ovarian reserve markers (AMH, FSH, AFC) in different age strata in IVF/ICSI patients. Int J Reprod Biomed (Yazd) 2016; 14: 501-6.

7. Brodin T, Bergh T, Berglund L, Hadziosmanovic N, Holte J. Menstrual cycle length is an age-independent marker of female fertility: results from 6271 treatment cycles of in vitro fertilization. Fertil Steril 2008; 90: 1656-61.

8. van der Steeg JW, Steures P, Eijkemans MJ, et al. Predictive value and clinical impact of basal follicle-stimulating hormone in sub-fertile, ovulatory women. J Clin Endocrinol Metab 2007; 92: 2163-8.

9. Ashrafi M, Madani T, Seirafi Tehranian A, Malekzadeh F. Follicle stimulating hormone as a predictor of ovarian response in women undergoing controlled ovarian hyper-stimulation for IVF. Int J Gynecol Obstet 2005; 91: 53-7.
10. van Montfrans JM, Hoek A, van Hooff MH, de Koning CH, Tonch N, Lambalk CB. Predictive value of basal follicle-stimulating hormone concentrations in a general subfertility population. Fertil Steril 2000; 74: 97-103.

11. Barbakadze L, Kristesashvili J, Khonelidze N, Tsagareishvili G. The correlations of anti-mullerian hormone, follicle-stimulating hormone and antral follicle count in different age groups of infertile women. Int J Fertil Steril 2015; 8: 393-8.

12. Frattarelli JL, Bergh PA, Drews MR, Sharara FI, Scott RT. Evaluation of basal estradiol levels in assisted reproductive technology cycles. Fertil Steril 2000; 74: 518-24.

13. Broekmans FJ, Kwee J, Hendriks DJ, Mol BW, Lambalk CB. A systematic review of tests predicting ovarian reserve and IVF outcome. Hum Reprod Update 2006; 12: 685-718.

14. Esposito MA, Coutifaris C, Barnhart KT. A moderately elevated day $3 \mathrm{FSH}$ concentration has limited predictive value, especially in younger women. Hum Reprod 2002; 17: 118-23.

15. Klein NA, Illingworth PJ, Groome NP, McNeilly AS, Battaglia DE, Soules MR. Decreased inhibin B secretion is associated with the monotropic FSH rise in older, ovulatory women: a study of serum and follicular fluid levels of dimeric inhibin A and B in spontaneous menstrual cycles. J Clin Endocrinol Metab 1996; 81: 2742-5.

16. Seifer DB, Lambert-Messerlian G, Hogan JW, Gardiner AC, Blazar AS, Berk CA. Day 3 serum inhibin-B is predictive of assisted reproductive technologies outcome. Fertil Steril 1997; 67: 110-4.

17. Corson SL, Gutmann J, Batzer FR, Wallace H, Klein N, Soules MR. Inhibin-B as a test of ovarian reserve for infertile women. Hum Reprod 1999; 14: 2818-21.

18. Visser JA, Themmen AP. Anti-Müllerian hormone and folliculogenesis. Mol Cell Endocrinol 2005; 234: 81-6.

19. van Rooij IA, Tonkelaar ID, Broekmans FJ, et al. Anti-Müllerian hormone is a promising predictor for the occurrence of the menopausal transition. Menopause 2004; 11: 601-6.

20. Pigny P, Jonard S, Robert Y, Dewailly D. Serum anti-Mullerian hormone as a surrogate for antral follicle count for definition of the polycystic ovary syndrome. J Clin Endocrinol Metab 2006; 91: 941-5.

21. Wang JG, Nakhuda GS, Guarnaccia MM, Sauer MV, Lobo RA. Müllerian inhibiting substance and disrupted folliculogenesis in polycystic ovary syndrome. Am J Obstet Gynecol 2007; 196: 77.e1-5.

22. van Rooij IA, Broekmans FJ, te Velde ER, et al. Serum anti-Müllerian hormone levels: a novel measure of ovarian reserve. Hum Reprod 2002; 17: 3065-71.

23. Nardo LG, Gelbaya TA, Wilkinson H, et al. Circulating basal antiMüllerian hormone levels as predictor of ovarian response in women undergoing ovarian stimulation for in vitro fertilization. Fertil Steril 2009; 92: 1586-93.

24. La Marca A, Giulini S, Tirelli A, et al. Anti-Müllerian hormone measurement on any day of the menstrual cycle strongly predicts ovarian response in assisted reproductive technology. Hum Reprod 2007; 22: 766-71.

25. Nelson SM, Yates RW, Fleming R. Serum anti-Müllerian hormone and FSH: prediction of live birth and extremes of response in stimulated cycles: implications for individualization of therapy. Hum Reprod 2007; 22: 2414-21.

26. Muttukrishna S, Suharjono H, McGarrigle H, Sathanandan M. Inhibin $\mathrm{B}$ and anti-Mullerian hormone: markers of ovarian response in IVF/ICSI patients? BJOG 2004; 111: 1248-53. 
27. Lekamge DN, Barry M, Kolo M, Lane M, Gilchrist RB, Tremellen KP. Anti-Müllerian hormone as a predictor of IVF outcome. Reprod Biomed Online 2007; 14: 602-10.

28. Vembu R, Reddy NS. Serum AMH level to predict the hyper-response in women with PCOS and non-PCOS undergoing controlled ovarian stimulation in ART. J Hum Reprod Sci 2017; 10: 91-4.

29. Griesinger G, Diedrich K, Devroey P, Kolibianakis EM. GnRH agonist for triggering final oocyte maturation in the $\mathrm{GnRH}$ antagonist ovarian hyper-stimulation protocol: a systematic review and meta-analysis. Hum Reprod Update 2006; 12: 159-68.

30. van Rooij IA, Broekmans FJ, Scheffer GJ, et al. Serum antimullerian hormone levels best reflect the reproductive decline with age in normal women with proven fertility: a longitudinal study. Fertil Steril 2005; 83: 979-87.

31. Haadsma ML, Bukman A, Groen H, et al. The number of small antral follicles (2-6 mm) determines the outcome of endocrine ovarian reserve tests in a subfertile population. Hum Reprod 2007; 22: 1925-31.

32. Hendriks DJ, Kwee J, Mol BW, te Velde ER, Broekmans FJ. Ultrasonography as a tool for the prediction of outcome in IVF patients: a comparative meta-analysis of ovarian volume and antral follicle count. Fertil Steril 2007; 87: 764-75.

33. Kwee J, Elting ME, Schats R, McDonnell J, Lambalk CB. Ovarian volume and antral follicle count for the prediction of low and hyper responders with in vitro fertilization. Reprod Biol Endocrinol 2007; 5: 9.

34. Maseelall PB, Hernandez-Rey AE, Oh C, Maagdenberg T, McCulloh DH, McGovern PG. Antral follicle count is a significant predictor of livebirth in in vitro fertilization cycles. Fertil Steril 2009; 91 (4 Suppl): 1595-7.

35. Gibreel A, Maheshwari A, Bhattacharya S, Johnson NP. Ultrasound tests of ovarian reserve: a systematic review of accuracy in predicting fertility outcomes. Hum Fertil (Camb) 2009; 12: 95-106.

36. Chui DK, Pugh ND, Walker SM, Gregory L, Shaw RW. Follicular vascularity-the predictive value of transvaginal power Doppler ultrasonography in an in-vitro fertilization programme: a preliminary study. Hum Reprod 1997; 12: 191-6.

37. Shrestha SM, Costello MF, Sjoblom P, et al. Power Doppler ultrasound assessment of follicular vascularity in the early follicular phase and its relationship with outcome of in vitro fertilization. J Assist Reprod Genet 2006; 23: 161-9.

38. Hendriks DJ, Mol BW, Bancsi LF, te Velde ER, Broekmans FJ. The clomiphene citrate challenge test for the prediction of poor ovarian response and non-pregnancy in patients undergoing in vitro fertilization: a systematic review. Fertil Steril 2006; 86: 807-18.

39. Jain T, Soules MR, Collins JA. Comparison of basal follicle-stimulating hormone versus the clomiphene citrate challenge test for ovarian reserve screening. Fertil Steril 2004; 82: 180-5.

40. Kwee J, Schats R, McDonnell J, Schoemaker J, Lambalk CB. The clomiphene citrate challenge test versus the exogenous follicle stimulating hormone ovarian reserve test as a single test for identification of low responders and hyper responders to in vitro fertilization. Fertil Steril 2006; 85: 1714-22.

41. Hendriks DJ, Broekmans FJ, Bancsi LF, Looman CW, de Jong FH, te Velde ER. Single and repeated GnRH agonist stimulation tests compared with basal markers of ovarian reserve in the prediction of outcome in IVF. J Assist Reprod Genet 2005; 22: 65-74.
42. Iliodromiti S, Anderson RA, Nelson SM. Technical and performance characteristics of anti-Müllerian hormone and antral follicle count as biomarkers of ovarian response. Hum Reprod Update 2015; $21: 698-710$.

43. Nelson SM, Fleming R, Gaudoin M, Choi B, Santo-Domingo K, Yao M. Antimüllerian hormone levels and antral follicle count as prognostic indicators in a personalized prediction model of live birth. Fertil Steril 2015; 104: 325-32.

44. Fleming R, Seifer DB, Frattarelli JL, Ruman J. Assessing ovarian response: antral follicle count versus anti-Müllerian hormone. Reprod Biomed Online 2015; 31: 486-96.

45. Jamil Z, Fatima SS, Cheema Z, Baig S, Choudhary RA. Assessment of ovarian reserve: anti-Mullerian hormone versus follicle stimulating hormone. J Res Med Sci 2016; 21: 100.

46. Fertility problems: assessment and treatment. Clinical guideline [CG156]. (February 2013). https://www.nice.org.uk/guidance/ cg156/chapter/recommendations. [Last accessed on 2018 August]. 